\title{
Silly Putty: Mobilization of the Known Across Technology-Enhanced Learning Spaces
}

\author{
MELANIE M. WONG \\ University of British Columbia
}

\begin{abstract}
In technology-enhanced classrooms, due to the affordances of technologies, English Language Learners (ELLs) are moving between learning spaces; boundaries are never clear. Questions arise with regards to how students' non-sanctioned experiences might mediate classroom learning. Using a multiliteracies (New London Group, 2000) and learning by design (Cope \& Kalantzis, 2015) theoretical lens, this ethnographic case study explores the technology-enhanced learning experiences of Grade 6 ELLs. Data including field observations, artifacts, and interviews were analyzed using thematic analysis (Saldaña, 2016). Findings of this study indicate that ELL students were engaged in learning experiences that encouraged them to mobilize their known (knowledge) across learning spaces.
\end{abstract}

Keywords

K-12, ELL, technology-enhanced, learning spaces

\section{Introduction}

Digital technologies are ubiquitous in contemporary times, particularly during a time of pandemic and post-pandemic realities. North Americans are bombarded by the constant flow of new technologies emerging on a regular basis. From smart phones to new internet applications, changes in computer operating systems. voice-controlled devices, social interaction and the ways of communication are changing. Scholars recognize and argue that technology continues to change over time and as result of these changes there are many affordances that become available for meaning making, both in the classroom and beyond (Abrams \& Russo, 2015; Lotherington \& Paige, 2017). Prior literature has noted how students (both English Language Learners (ELLs) and non-ELLs) have continued to use technology outside of the classroom (Abrams, 2016; Black, 2008; Ito et al, 2013; Jenkins et al, 2016; Lam, 2000; Lam, 2009; Lam \& Warriner, 2012; Lange, 2014; $\mathrm{Yi}, 2009$ ) for a variety of purposes (e.g., communicating with transnational peers, writing fan fiction, etc.). However, questions are still prevalent with regards to the implications of technology in a K-12 ELL classroom, more specifically an elementary context. Although technology has also become a part of the classroom context where students (ELL or not) are using SMART boards, iPads, computers and hand-held devices to engage in meaning making, there is still a research gap with regards to our understanding of the reality of technology usage in the classroom. In particular, there is a knowledge gap with regards to the learning experiences that occur in Kindergarten to Grade 12 (K-12) ELL technologyenhanced classroom environments. 
Although digital technology is prominent in these technology-enhanced environments, traditional means of meaning making are still available (e.g., paper and pencil). In these environments, students are provided with more options to engage in their meaning making including both digital and non-digital tools. One of the affordances of digital technologies is that it enables students to move between a variety of learning spaces (digital or not); the boundaries between these learning spaces are never clearly defined. Therefore, students are not confined to the physical walls of a classroom but rather they can mobilize knowledge and themselves across learning spaces. This mobilization of knowledge and people across learning spaces means that informal learning experiences can potentially mediate school-sanctioned learning.

The following article examines the learning experiences of grade 6 ELL students in a technology-enhanced classroom and focuses on one illustrative example, Silly Putty, which is taken from a larger ethnographic case study. Silly Putty, used as the illustrative example here, is also a toy that has unique physical properties (e.g., it bounces, it can flow). In this illustrative example, I argue that the learning experiences and the affordances of this technology-enhanced classroom invited ELL students to mobilize their knowledge across learning spaces, their known, into the classroom. Their known includes their own knowledge and the knowledge of experts outside of the classroom (family members and online experts) as well as knowing when it is appropriate to use which communicative repertoires (Rymes, 2012) (e.g., what register to use in the classroom or emailing a friend).

This paper is organized as follows: 1) a detailed discussion of the literature will be presented in the following areas: learning spaces, multiliteracies, learning by design, and the known; 2) a description of the research question, research context, research data and data analysis; 3) the illustrative example, Silly Putty, a rich school-sanctioned learning experience is explored; 4) a discussion of the findings and implications for future research and instructional practice; 5) concluding remarks. In the next section, I will discuss the literature starting with conceptualizing a learning space.

\section{Learning Spaces}

The concept of learning spaces (Compton-Lilly, 2014; Gee, 2004; Erstad et al., 2016; Lemke, 2004; Sheehy \& Leander, 2004) is not a new one. Prior literature has documented that scholars have explored the movement of people, notions, and practices between various learning spaces. Digital technologies have changed the concept of learning spaces. Learning spaces can occur virtually and within other physical spaces, therefore learning spaces can also be abstract and move. It is suggested that there are no clear boundaries as people, notions and practices move between a variety of informal learning spaces (Erstad et al., 2016). Although scholars have addressed learning spaces in a variety of ways (e.g., World of Warcraft, online chatrooms, etc.), many are unable to fully address the complexities of learning spaces and the implications that they might have in a classroom. In a technology-enhanced classroom, learning spaces are constantly changing and are not static; technology has provided additional affordances for this to happen. Students are not restricted to physical learning space but are able to move between the seemingly invisible borders to other learning spaces (both virtual and physical).

I make a distinction between school-sanctioned and interstitial learning spaces (Wong, 2019, 2020). Learning spaces that are institutionally bound are school-sanctioned 
learning spaces. In these spaces, one would conventionally see "school-based activities" occurring, such as completing a science worksheet or creating a PowerPoint presentation to show one's understanding of a mathematical concept. However, traditional pencil and paper activities are not necessarily the activities that occur in digitally mediated learning spaces; rather these activities have evolved due to the affordances of various electronic technologies. Interstitial learning spaces are those spaces that include hallways, the back of the classroom, and outside of school spaces that are not necessarily institutionally bound. These are often where "unofficial" learning occurs. All of these spaces can be virtual or physical. The boundaries are often invisible or unclear between various learning spaces with movement that may occur seamlessly. I argue that both school-sanctioned and interstitial learning spaces help to enhance our understandings of the learning experiences that occur in technology-enhanced classrooms, particularly in how knowledge can be mobilized across learning spaces within and across the physical walls of a classroom.

\section{Multiliteracies, Learning by Design and the Known}

In the New London Group's (1996) seminal article, where they coined the term 'multiliteracies', the authors argued that in the contemporary context, in response to changing global and communicative landscapes, a new approach to literacy pedagogy was required. These landscapes are characterized by social, linguistic, and cultural (as well as sub-cultural) diversity and multimodal (e.g., visual and linguistic) communications associated with multimedia and information technologies. The latter, they argued, relates closely back to the former, as it supports and extends cultural and sub-cultural diversity. In this context, they stated that "the languages needed to make meaning are radically changing in three realms of our existence: working lives, public lives (citizenship) and private lives (lifeworld)" (p. 65). The New London Group defined lifeworld as "spaces for community life where local and specific meanings can be made" (p. 70). Increasingly included amongst these community lifeworlds (home, professional school, interest, affiliation) (Cope \& Kalantziz, 2009), are the interstitial learning spaces where K-12 students engage in meaning making such as fan fiction websites (Black, 2008), Minecraft, (Abrams, 2016), online chatrooms (Lam, 2004) and World of Warcraft (Nardi, 2019). In lifeworlds such as these, students are producers, as well as consumers, of multimodal texts, using different digital tools and platforms. However, lifeworlds are not limited to digital spaces and include the many different interstitial learning spaces (e.g. within their home or religious community) where K-12 students engage in meaning making. Such lifeworld experiences are often rich and engaging for K-12 students.

In their discussion, the New London Group (1996) acknowledged the significance of lifeworld practices and addressed what schools can do. They argued that schools have always played a critical role in determining students' life opportunities. Therefore, they indicated that in order for learning to be relevant, the learning processes that are used need to "recruit" rather than erase or ignore the different subjectivities. The New London Group defined different subjectivities as interests, intentions, commitments and purposes that students bring to the classroom. Here, the New London Group also indicated that these different subjectivities needed to mesh with curriculum and with the "attendant languages, discourses and registers, and use these as resources for learning" (p. 72). It is further argued that this is necessary for a pedagogy that opens the potential for greater access. Hence, 
schools need to incorporate opportunities for students to bring in [recruit and mobilize] their multiple lifeworld knowledge and experiences (practices), and their different subjectivities. Therefore, the known has the potential to impact the learning that occurs in another learning space, whether school-sanctioned or not. This known is unique to each child; it is individual and shaped by the multiple community lifeworld experiences an individual might have. Due to the affordances of digital technologies, entry to different cultures and sub-cultures is more accessible and the traditional known that teachers are familiar with is likely to have changed. Students are now bringing in known that could potentially include lifeworld experiences in digital learning spaces. For example, students are engaging in Minecraft in out-of-school contexts (Abrams, 2016) and as a result the skill of using pixelated blocks to construct buildings can be mobilized into a school-sanctioned learning space to complete assignments (Petrov, 2014).

The following study incorporates a Learning by Design (Cope \& Kalantzis, 2015) theoretical lens to better understand the student learning experiences in this technologyenhanced classroom but more specifically how students potentially mobilize knowledge (part of their known) across learning spaces into a school-sanctioned one. Cope and Kalantzis $(2009,2015)$ extend on the work theorized by the New London Group (1996, 2000) by expanding and building on the "how" of multiliteracies. They emphasize that the multiliteracies approach is comprised of processes of teaching and learning that go back and forth, between and across, various knowledge processes and pedagogical moves. Building on the four components of the multiliteracies pedagogies as articulated by the New London Group (1996, 2000), Cope and Kalantzis (2009; 2015) have extended the notions of situated practice (experiencing), overt instruction (conceptualizing), critical framing (analyzing), and transformed practices (applying). As they apply these notions to curriculum practices (the "how" of multiliteracies), they translate these notions into what they term knowledge processes. Knowledge processes are activities an individual does in order to know (Cope \& Kalantzis, 2015; Kalantzis \& Cope, 2020). However, they also argue that no matter what terms are used to categorize learning activity types, the crucial idea in a multiliteracies and learning by design approach is that learning involves this notion of "weaving" across different pedagogical moves.

Cope and Kalantzis (2015) argue that "pedagogy is the design of learning activity sequences. Two questions arise in the process of pedagogical design: which activities to use and in what order?" (p. 17). They add that the concept of learning by design is a classification of activity types. For the purposes of this study, such a classification is a very helpful conceptual framework, especially when examining and analyzing the learning experiences in a technology-enhanced classroom. I refer to these knowledge processes (experiencing, applying, conceptualising, and analyzing) to better understand the related activity types activated in my research site. Below is a table that summarizes the knowledge processes (Table 1). 
Table 1

Knowledge Processes (Cope \& Kalantzis, 2015)

\begin{tabular}{|l|l|}
\hline \multicolumn{1}{|c|}{ Knowledge Processes } & \multicolumn{1}{c|}{ Definition } \\
\hline Experiencing the Known & $\begin{array}{l}\text { Incorporating opportunities for students to } \\
\text { draw on their previous experiences or the } \\
\text { "familiar." }\end{array}$ \\
\hline Experiencing the New & $\begin{array}{l}\text { Introducing a learner to a topic that is less } \\
\text { familiar. Learning occurs with these activity } \\
\text { types when it is scaffolded. }\end{array}$ \\
\hline Conceptualizing by Naming & $\begin{array}{l}\text { Defining and learning to use abstract and } \\
\text { generalized terms. This activity type also } \\
\text { includes categorizing similar and differences } \\
\text { and labeling a diagram. }\end{array}$ \\
\hline Conceptualizing by Theory & $\begin{array}{l}\text { Asking a learner to link the concept name into } \\
\text { the language of generalization (e.g., concept } \\
\text { maps, putting concepts together, drawing a } \\
\text { diagram). }\end{array}$ \\
\hline Analyzing Functionally & $\begin{array}{l}\text { When a learner is reasoning, drawing } \\
\text { inferential and deductive conclusions, } \\
\text { establishing cause and effect. }\end{array}$ \\
\hline Analyzing Critically & $\begin{array}{l}\text { When a learner critically considers human } \\
\text { interests and intentions- their own and other } \\
\text { people's (e.g., identify the gaps). }\end{array}$ \\
\hline Applying Appropriately & $\begin{array}{l}\text { When a learner applies knowledge in the } \\
\text { "usual" way to see whether it works in a } \\
\text { predictable way in a conventional context. (e.g., } \\
\text { solving a math problem) }\end{array}$ \\
\hline $\begin{array}{l}\text { Using knowledge you have learned and } \\
\text { applying it into another context. }\end{array}$ \\
\hline Applying Creatively & \\
\hline
\end{tabular}

Exploring the knowledge processes activated by students will help to better understand how knowledge is mobilized across learning spaces in this classroom. In the remaining sections of this article, I will be discussing the illustrative example, Silly Putty, illuminating the knowledge processes activated by students.

\section{Research Method}

\section{Research Questions}

The following research question will be addressed in this article:

1. In what ways do learners mobilize knowledge (a part of their known) across learning spaces?

I will elaborate on the answers to this research question for the remainder of this article.

\section{Context}

The following illustrative example, Silly Putty, has been chosen to provide the reader with a better understanding of the learning experiences that occurred in this technology-enhanced classroom. Duff (2012) argues that the real business of case study 
research is the notion of "particularization" and not generalization. It is about choosing a particular phenomenon or case and getting to know it well (Stake, 1995).

This illustrative example, Silly Putty, was taken from a larger ethnographic case study (Duff, 2008; Heath \& Street, 2008) which investigated the learning experiences of grade six ELL students in a technology-enhanced classroom. The study was conducted in a Western Canadian middle school which had a linguistically and ethnically diverse population. For the majority of the students in this school, English was not their first language. The ELL students in this classroom had intermediate to advance English language proficiencies according to school district and provincial assessments. At Cypress Hills (pseudonym) school, I recruited five teachers and twenty-five students in one classroom. All of the names used in this paper are pseudonyms selected by the participants which reflect their identities/interests. In this paper, I focus on three students, Eddy Teddy, rainbow unicorn, and Starfire (pseudonyms) and one teacher, Miss Green (pseudonym).

Cypress Hills school was a technology-rich environment. The school and school district invested in multiple digital technologies including, but not limited to, SMART boards (interactive white boards), iPads, and Apple computers. In this technologyenhanced classroom students incorporated digital and non-digital tools as part of their daily meaning making processes (e.g., using iMovie to create videos to demonstrate their understanding of local government, using Scratch to program and show their understanding of geometrical shapes, etc.).

\section{Data}

Data collection occurred between January 2015 to June 2015. In this paper, I will only elaborate on the data that was used for this illustrative example. However, the larger study included a number of data collection strategies. Decisions with regards to data collected were made based on the age of the participants. My data for this article consisted of field observation, artifact collection (visual artifacts, email exchanges) and informal and formal interviews (which were transcribed and analyzed). Analytic memos were kept during the entire process. Saldaña (2016) described these memos as "potential sites in which rich analysis may occur" (p. 45).

\section{Data Analysis}

Once data reduction had been completed, data (including transcribed interview transcripts, visual artifacts and textual artifacts) was analyzed using thematic analytic techniques (Saldaña, 2016). I used deductive analysis and coded the data using the "knowledge processes" (Cope \& Kalantzis, 2015). I also used inductive analysis and coded the data to identify salient themes.

\section{Introducing Silly Putty}

The following sections contains excerpts from my researcher journal and field notes. The intent is to provide the reader with a better understanding of the social context as well as the illustrative example, Silly Putty.

On an early February afternoon, February $10^{\text {th }}$ to be exact, the students were gathered in Miss Green's room for their business elective class. Although this was in the initial stages of my data collection period, I was already familiar with many of the routines 
in this class. The grade 6 students from all of the classes had daily option blocks. There were many option choices including Foods, Construction, Photography, Robotics, Pottery, and Digital Literacy. All students were required to take one Physical Education class yearly. The school ran in a semester system with regards to the options. During my time at the school, the students changed their options once and this occurred in early March.

Today when I entered the classroom after visiting the Pottery option class, I found the groups hard at work on their business project. Each group of students were required to create a product, advertise it and sell it. As I entered the classroom, Eddy Teddy, rainbow unicorn and Starfire eagerly invited me to join their group. It was during this conversation that I was introduced to Silly Putty.

To better understand the project the students were working on in this business class, I had a conversation with Miss Green (the teacher). During this conversation she presented me with the assignment directions (see Figure 1 for a sample page from the multiple page assignment directions). I learned that Miss Green expected her students to come up with a product, market it, and then sell it. She provided the students with clear guidelines about the assignment expectations, including instructions to create a logo, have a name for your business, and create an information poster and website. She also wanted the students to reflect on how they were working together as a group and how they were performing as a business (e.g., How can we increase sales?). Miss Green provided students with opportunities to apply curricular concepts to a specific context (applying creatively). However, Miss Green also provided opportunities for experiencing by targeting such knowledge processes as experiencing the new. Creating a business product and selling it was not a foreign concept to these students; however, many of them had never done it before. Therefore, before this assignment, Miss Green explained the concept of creating a business product through a variety of mini-lessons and pre-assignments. Miss Green encouraged her students to engage in conceptualizing by naming. She scaffolded the learning by teaching the students vocabulary such as 'product', 'selling', 'marketing', and 'mark up.' As I have already mentioned, ELL students in this class were at intermediate and advance language proficiency levels. According to school assessments, these students were working on building their academic language and subject-specific vocabulary (e.g., such as business vocabulary). It is suggested that when Miss Green had her students' engaging in conceptualizing by naming, she was addressing their English language proficiency levels. Miss Green also provided clear guiding questions in her assignment, such as-What does your business sell or do? What prices will you charge? These questions appeared to help to scaffold and support students' learning and also kept students on track as they figured out their business products and plans. By scaffolding the language and providing guiding questions, Miss Green encouraged her learners to gain explicit information and also engage in guided practice (The New London Group, 2000). 


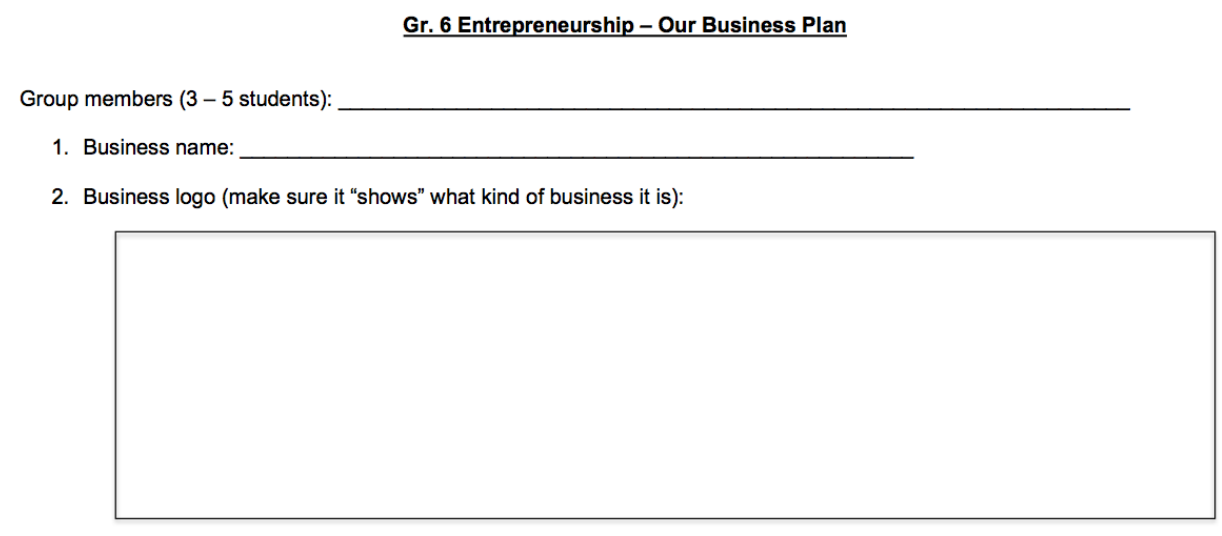

3. What does our business sell or do?

4. Who will our customers be?

5. How much will we need for start-up costs? What materials do you need to start your business? Where should Ms. Green buy these materials?

Figure 1. Miss Green's Assignment Directions (page 1)

In the entrepreneurship assignment, Miss Green targeted the activity type analyzing critically, so that the students doing this project were required to critically evaluate other people's perspectives to create a product and market it. Students also activated the activity type applying creatively, using their understanding of a business to create a product and market it to a particular audience. By targeting these knowledge processes, Miss Green was also inviting students to engage in reflexive pedagogy (Cope \& Kalantzis, 2015) as these students were engaged in hands-on activities, analyzing the interests of people and transferring their business knowledge into an appropriate context.

Cope and Kalantzis (2015) also discuss how "one key pedagogical weaving is between school learning and the practical out-of-school experiences of learners ... cultural weavings" (p. 4). Miss Green's assignment was "open-ended"- - the business product could be whatever the students wanted to create-with many opportunities for students to activate experiencing the known. In this classroom, as I discuss below, students engaged in this activity type as they brought in their experiences from outside of the classroom to support the development of this business product.

I was introduced to the origins of Silly Putty through a discussion during that early February visit described earlier. Eddy Teddy, rainbow unicorn and Starfire were all in the same group. When I entered the classroom, they were situated at a dark grey cloud shaped table close to the door on the left-hand side of the classroom. Eddy Teddy invited me to join them. The table was filled with containers and materials to create their product, Silly Putty. When I joined them, the girls were hard at work making Silly Putty (see Figure 2 below). I decided to seek some clarification regarding the origins of their business venture. 
Eddy Teddy, always keen to answer, explained, “. . . cuz one night I was on this on a like YouTube and it was like when (Miss Green) told us about business and I was on this channel thing and it was it was like talking about how you can make your own silly putty so I got an idea right there and I was like okay let's make silly putty because it's like five dollars in stores and for only a little bit so like why can't we get so much for only like cheap." In her explanation, Eddy Teddy used YouTube-specific vocabulary like "channel," demonstrating her familiarity with this particular learning space and the register used to communicate (navigating YouTube was part of her communicative repertoire [Rymes, 2012]). Here, this salient theme of seeking information using internet sources is illuminated. I then asked if Eddy Teddy could send me the YouTube channel where she found this Silly Putty idea. Starfire agreed to do this, but indicated that "there is like so many." Eddy Teddy then explained, "it's called a Howcast." But again I insisted, "okay can you send me the howcast that you found." Starfire responded by providing me with the search terms to find it on YouTube, "how to how to make silly putty." I again asked if it was possible for the girls to share this YouTube video with me since it would not be the ". .. same one that gave you this inspiration" otherwise. Finally, Eddy Teddy wrote the search terms for the Howcast on a piece of paper for me (see Figure 3). When Eddy Teddy gave me the exact search terms to type to find the "Howcast," I learned that these "search terms" were a part of Eddy Teddy's (and Starfire's) technological knowledge, her (their) known. She was familiar with how to navigate the search functions in YouTube to obtain the information she needed and the YouTube channels she wanted to access. The significance of this instance is that students like Eddy Teddy mobilized her known (effectively seeking information using internet sources, in this case, YouTube) from one learning space to another. After Miss Green assigned the learning task of creating a product and selling it, Eddy Teddy activated the activity types experiencing the known and applying appropriately and used YouTube to find a business product idea for her group. She drew on technological knowledge acquired in her interstitial learning spaces to support a learning task in a school-sanctioned learning space. Another salient theme is highlighted here, where students in this classroom were accessing expert informants on the internet outside of the classroom. What is important about this practice is that experts are not always in school-sanctioned learning spaces but can be found in a variety of other learning spaces, including YouTube, and that students are accessing these interstitial experts to support the learning in the classroom. Essentially, the teachers have given the students the option to deploy the technology expertise they have developed outside of the classroom to complete their school-sanctioned tasks. 


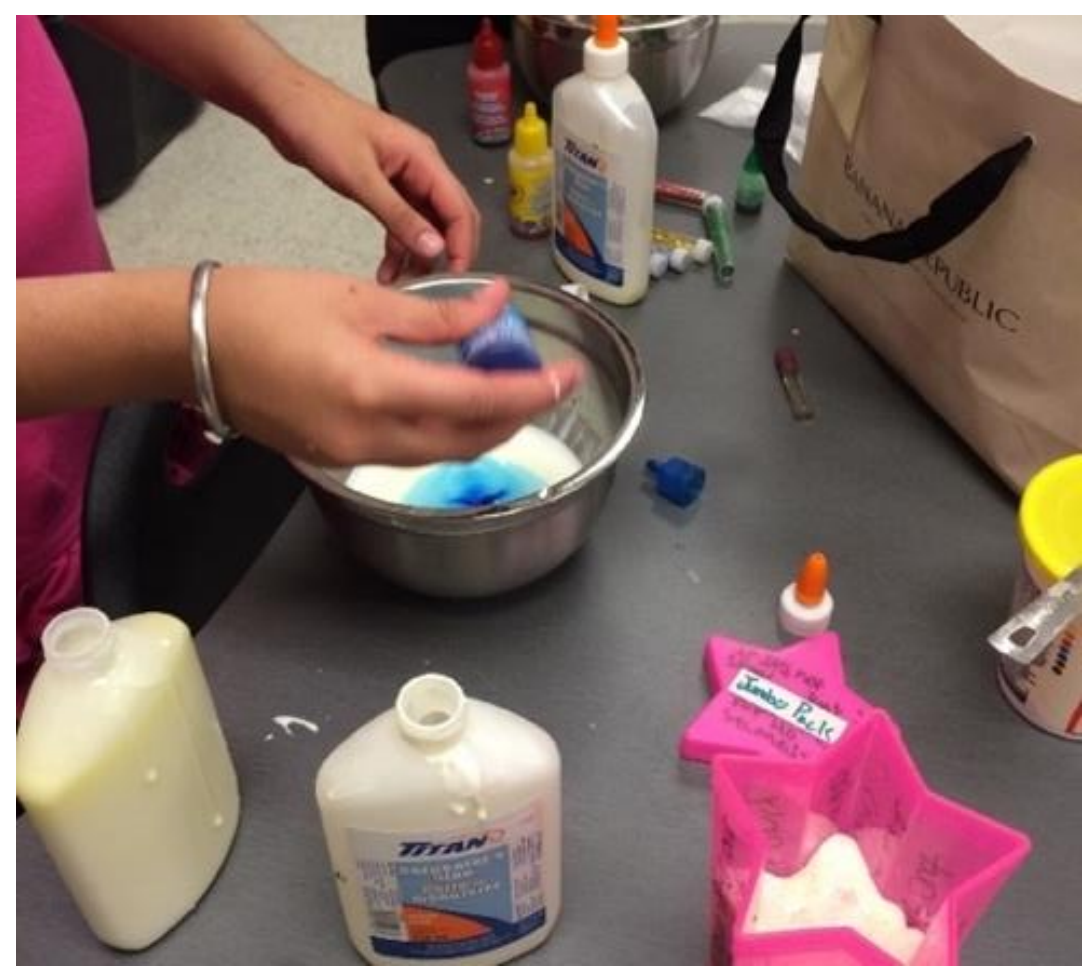

Figure 2. Making Silly Putty

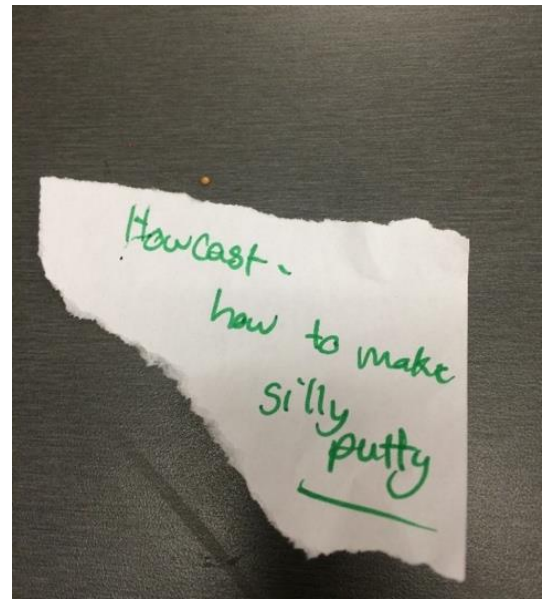

Figure 3. Howcast Search Terms 


\footnotetext{
Gooey Nerds = Silly Putty

Surprise Putty \& silly putty- comes with free containers

Jumbo Pack - $\$ 3.00$

medium Pack - $\$ 2.00$

small Pack - $\$ 1.50$

Limited offers are for $\$ 2$ for any size

Glow in the dark-Jumbo Pack 3.50 medium Pack 2.50 small Pack 2.00
}

What is silly putty? silly putty is slime that does not stick. It comes in varieties of colours and you can have different coloured glitter for free. (The glitter is optional) You can also get all the colours in one so a rainbow. Its the same price as normal silly putty.

What is surprise putty? Surprise putty is like kinder surprise just instead of the chocolate we have slime

Normally in stores you pay 5 or 10 dollars for silly putty. We give you the best offers.

Receive a coupon for $50 \%$ off on a regular price for next purchase.
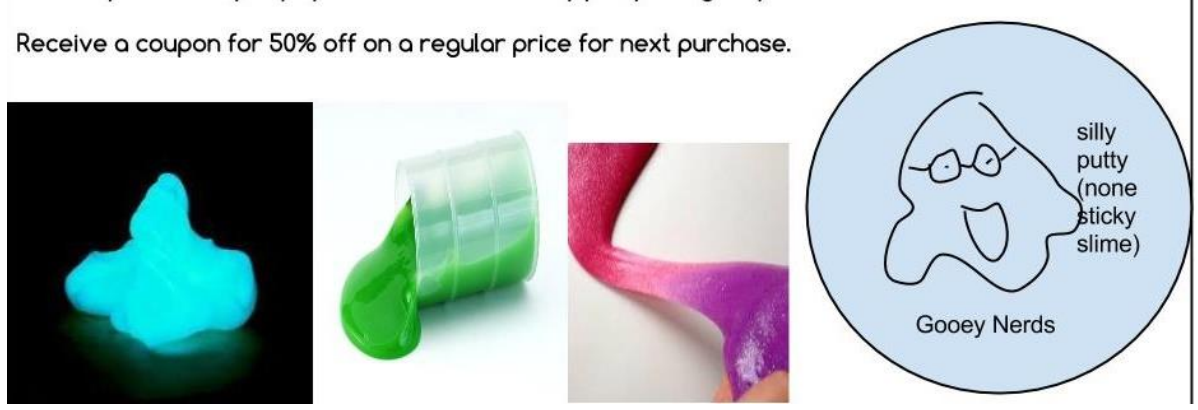

Figure 4. Gooey Nerds Advertisement

Figure 4 shows a business advertisement that the girls created; one of the assignment requirements Miss Green gave her students was to create an information poster. This image is significant because of how the girls used a register appropriate for the purpose. Phrases such as "limited offers for $\$ 2$ for any size," "it comes in a variety of colours and you can have a different coloured glitter for free, "and "receive a coupon for $50 \%$ off on a regular price for next purchase" demonstrate how the girls were familiar with the register appropriate in sales; this was part of the girls' known. The girls also created a business slogan, "silly putty [none sticky slime]" and a company name "Gooey Nerds."

When considering the image from the standpoint of its site of production (Rose, 2016), it was created digitally and used a combination of both text and images (found by using Google and searching for the coloured images of Silly Putty). The multi-coloured pictures of Silly Putty at the bottom draw the viewer's gaze downwards. As Kress \& van Leeuwen (2006) note, "The [producer] uses the image to do something to the viewer. It . . . 'demands': the participant's gaze ... demands something from the viewer ..." p. 120). The "demand" from the viewer is to look at those coloured images of Silly Putty that they could purchase. In this example of visual data, I learned that a variety of digital modes (Kress, 2011) were used, both text and images, in this classroom to engage in meaningmaking.

In a follow up conversation about the Silly Putty project, I asked the girls (Eddy Teddy, Starfire, and rainbow unicorn) to join me for a focus group interview in the conference room. On my laptop, I showed the girls some of the data I had collected. I asked if the girls could elaborate more on the process through which they created the 
advertisement (Figure 4). Starfire explained that she had to redo her peer's work since it was not accurate, "not the actual prices." She also indicated how she felt it was important to include pictures of "slime" (or Silly Putty) since it resembled what the product was actually going to look like. We also discussed the creation of the logo: the girls used Google Drawing to create this image, and the idea originated from Eddy Teddy who "started drawing it." We talked about who apprenticed the girls, in particular Starfire, to write in the business register previously noted in the advertisement (Figure 4). Starfire indicated it was her dad. She further reflected on the role her father played in this process by saying that "he's good with ideas so I asked him." Her father's advice was to "be professional," and "before people ask a question it should be answered already." In this interstitial learning experience (at home), the activity type, experiencing the new, was activated. As the expert, Starfire's father helped her to be consciously aware of what was important in business, but he also acted as a guide by explicitly teaching her what was important: for example, before people ask a question it should be answered already. In this way, Starfire was apprenticed into the business register that was crucial for her to know as a member of her business class. She activated the knowledge processes of experiencing the known and applying appropriately by taking knowledge (from home) and bringing it into a classroom to complete her business assignment. Here, the salient theme of accessing family experts outside of the classroom is illuminated.

By contrast, a different register is used in a follow-up email exchange between the girls and me (Figure 5): 


\section{Silly Putty?}

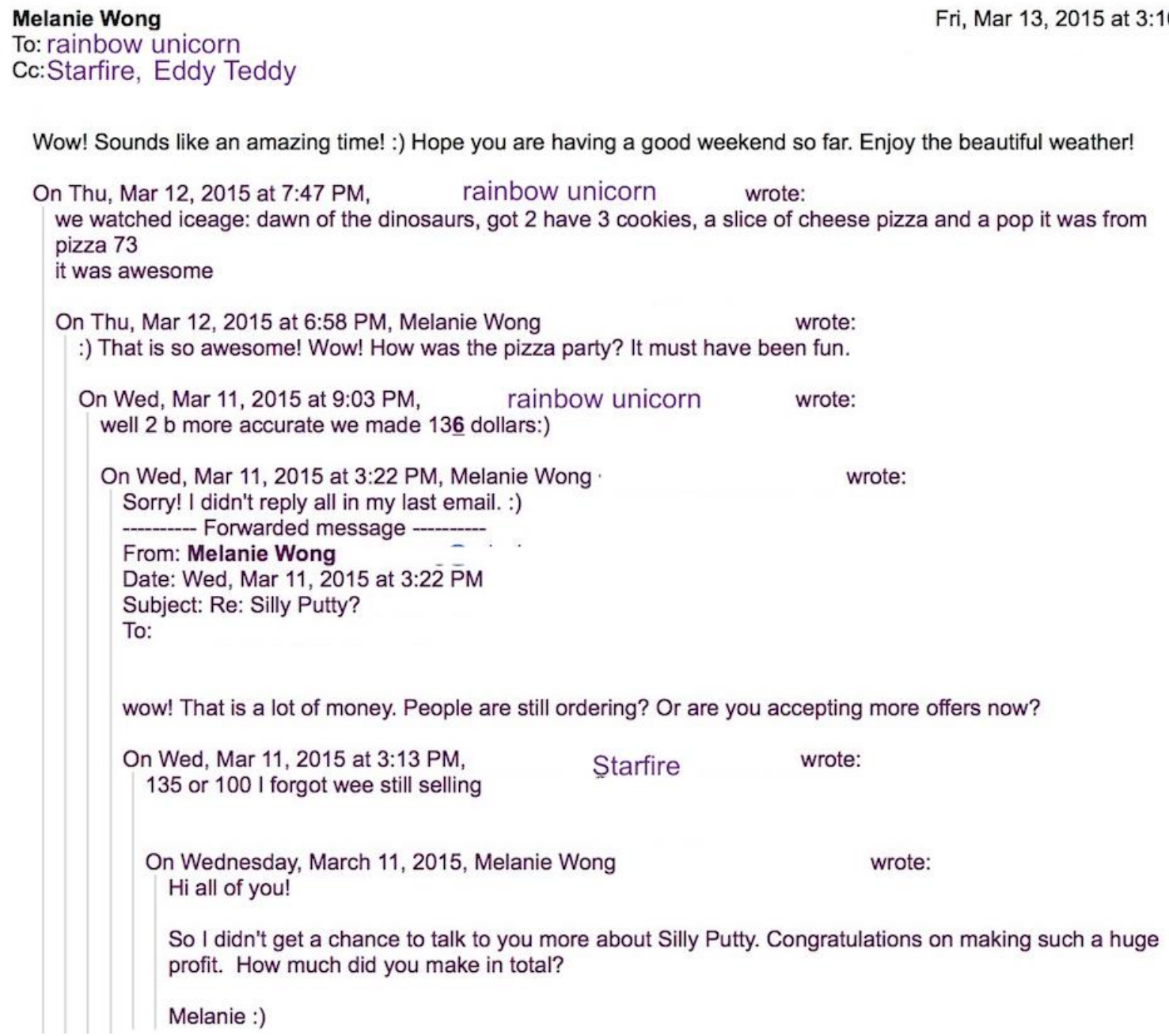

Figure 5. Email Exchange (March $13^{\text {th }}$ )

My initial email to the girls, captured at the bottom of this image/email thread, asks how much money they made selling Silly Putty. This initial exchange shows formality; I include a salutation and sign my name at the end. In response to my email, Starfire replied with no salutation and very informally, with incomplete sentences and spelling errors (e.g., "wee"). Following Starfire's email, rainbow unicorn replied to the thread. Note the "Netlish" (Crystal, 2006) usage of " 2 " "b" and how rainbow unicorn bolded the number 6 to correct Starfire's initial response about the amount of money they had made. Also note the emoticon usage, a smile created using a colon and bracket. The register in this exchange is very different than the more formal one of the business advertisement (Figure 4). The different registers these girls were familiar with demonstrate their various communicative repertoires built from interactions with others (Rymes, 2016), which it is suggested are linked very much to the known that individuals carry from one learning space into another. As these students participated in many interstitial learning spaces, they often used "Netlish" 
(Crystal, 2006) or emoticons and a variety of communicative repertoires that were not necessarily those they used in school-sanctioned spaces.

Reflecting on this informal register indicates many affordances (Kress, 2011) when using both textual (Netlish) and visual (emoticons) modes. For example, messages are faster to type using the number 2 rather than typing the entire word "two"; emoticons can express a greater range of emotions than just text. These affordances have many potential implications for classroom practice, especially if teachers recognize that their students come with a variety of communicative repertoires. In the multiliteracies literature, the New London Group (2000) speaks about the concept of available design, which are the resources for design, and explain how schools are crucial sites in which discourses relate to each other: "Available designs also include another element: the linguistic and discoursal experience of those involved in Designing, in which one moment of Designing is continuous with and a continuation of particular histories. We can refer to this as intertextual context (Fairclough, 1989), which links the text being designed to one or more series ('chain') of past text" (p. 21).

In the informal email exchange above, my participants knew it was appropriate to use an informal register, such as Netlish and emotions, when communicating with me (see Figure 5). This informal register, used in interstitial learning spaces outside of school, contrasts significantly from that of the advertisement (Figure 4), which used a more formal register appropriate for a school-sanctioned business class. This use of a formal business register, it is suggested, can be attributed to the knowledge processes Miss Green targeted. In our initial discussion (I mentioned above) and the original assignment instructions (see Figure 1 for a sample page), Miss Green suggested that students "check out some websites of businesses you know," thus encouraging them to activate the activity types of experiencing the known and applying appropriately. She was therefore inviting the students to look at a familiar business website and apply what they saw to their own business website. She also explicitly taught the necessary business vocabulary (see Figure 1 for where she bolded key vocabulary words) because she wanted her students to apply this language to their assignment. In so doing, Miss Green was encouraging her students to use the appropriate business register. Here, the salient theme of applying a range of multimodal communicative repertoires is illustrated. However, this illustrative example also shows that Starfire's father supported Starfire's learning where Starfire accessed a family expert outside of the classroom. Starfire's father encouraged the knowledge process of experiencing the new when he, as the business expert, explicitly taught Starfire what a business register was ("be professional" and "before people ask a question it should be answered already").

\section{Discussion and Implications}

In this illustrative example, Silly Putty, I have discussed the various knowledge processes that were activated by the elementary ELL students due to their teacher's task design. It is noted that these ELL students used a range of knowledge processes. However, to answer my research question, I have also discussed the mobilization of knowledge (part of the known) from one learning space to another (school-sanctioned or interstitial). Due to the affordances of digital technologies and their teacher's task design, ELL students, Eddy Teddy and Starfire, activated the knowledge processes, experiencing the known and 
applying appropriately, where they took their known they had learned in other learning spaces, such as finding information on YouTube Howcasts (seeking information using internet sources), and applied this known to the school-sanctioned task of creating a business project. This movement of knowledge across learning spaces is crucial to supporting these ELL students as it provides an entry point for these learners and I will elaborate on this further below. Scholars (Erstad et al., 2016) have addressed the movement of people and ideas in the context of learning; specifically addressing how learning happens when people move in and out of sites of learning. As Erstad et al. (2016) argue, "connecting learning across school and out-of-school contexts is a growing concern in education research and practice" (p. 27). Like the participants in Dyson's (2013) study, my participants have "recontextualized or borrowed voices, images, themes and intentions initially [associated] with other [practices] . . . The children found resources in varied aspects of local (if globally influenced) child cultures" (p. 164). Therefore, an implication of this illustrative example calls on educators to address multiple literacies, such as digital, and not focus solely on traditional print-based literacies (Dyson, 2004, 2013), since students are already carrying these multiple literacies in their known. This expanded focus starts with teachers getting to know their students (ELL or not) better (e.g., such as their experiences in interstitial learning spaces) and then encouraging opportunities to bring in their prior experiences (their known). In this illustrative example, ELL students such as Eddy Teddy and Starfire, drew on their known and used it to support their learning; this opportunity to draw on their known was a key pedagogical move made by their teacher to support her ELL students. This type of pedagogical move has been documented in the literature as being helpful to ELL students (Gibbons, 2015) because it provides an entry point for these students that might not necessarily have the same experiences (known) as their native speaker peers. This has also been emphasized in the literature where the "skills" and lifeworld experiences students possess can be used as strengths that can be expanded in the classroom context and used to connect with different academic skills (Cummins \& Early, 2011; Cummins, et al., 2015; García-Sánchez \& Orellana, 2019). As this study is one that focuses on the learning experiences in a technology-enhanced classroom, it is argued that digital technologies may provide the affordances for students to bring their known into the classroom. For example, by using the digital technologies available, students such as Eddy Teddy were able to search for ideas on YouTube, accessing external experts, to support a school-sanctioned project which would not have occurred if digital technologies had not been utilized. This is significant in a pandemic and post-pandemic world where digital technologies have become ubiquitous in many K-12 settings. School districts around the world have had to move between in-person, hybrid and remote learning spaces due to fluctuating COVID-19 infections. Therefore, it becomes increasingly important for educators to consider making intentional pedagogical moves to support their ELL students by purposefully using the affordances of digital technologies but also providing opportunities for these students to bring in their known (such as their technological skills to search for information on YouTube).

A significant implication from this study is the influence of outside individuals on the school-sanctioned learning spaces. From a father teaching his daughter the appropriate register to sell a product to an internet "unknown" YouTube expert providing a business product idea, the known played a crucial role in the classroom: in particular, the completion 
of school-sanctioned assignments. As previously mentioned, these "experts" were not always in the classroom but rather were invited into a school-sanctioned learning space. Scholarship (García-Sánchez \& Orellana, 2019; Hyvärinen et al., 2016; Marshall \& Toohey, 2010) also reflects the need for teachers to embrace their students' prior experiences and invite family members (parents, grandparents, etc.) to play a more active role within the classroom. On a practical level, this might involve teachers cultivating opportunities to create Identity Texts (Cummins \& Early, 2011) and inviting parents or grandparents to be a part of this process. As explained by Cummins and Early, Identity Texts are "described [as] the products of students' creative work or performances carried out within the pedagogical space orchestrated by the classroom teacher." Students invest their identities in the creation of texts- which can be written, spoke, signed, visual, musical, dramatic, or combinations in multimodal form" (p. 3). These Identity Texts can reflect students' identities in a positive light and is one way for teachers to intentionally invite students to bring in their known.

However, I also want to acknowledge that these new digital resources for learning, such as using YouTube to find information, also have pitfalls. For examples, when students are searching online for information there is the potential to encounter misinformation such as Deepfakes (Yadlin-Segal \& Oppenheim, 2020). With Deepfakes, audiovisual manipulating artificial intelligence (AI) applications synthesize multiple audiovisual products into one manipulated media, which is usually in the form of a video (Yadlin-Segal \& Oppenheim, 2020, p. 2). These "fake videos" show a person doing/saying something they have never said or done. Deepfakes pose great issues in terms of ethics and the spreading of misinformation. They are also a potential concern when it comes to K-12 students searching for information using online sources such as YouTube. Teachers need to be aware of this and engage in regular digital citizenship lessons (Ribble, 2011) with their students on how to appropriately search for information online to alleviate potential issues. In a pandemic and post-pandemic world, there is an increasing need for educators to address how to use digital technologies appropriately as many schools are being utilizing a range of technologies to support learning.

\section{Conclusion}

The following article has highlighted how elementary ELL students in technologyenhanced classrooms are tapping into their interstitial lifeworld experiences to complete their school-sanctioned assignments; mobilizing this known to support school-sanctioned activities. Their known includes their digital lifeworld experiences in interstitial learning spaces that teachers may not be familiar. There is an urgent need, especially as a result of the COVID-19 pandemic, to better understand the learning experiences that occur in technology-enhanced environments since many of our K-12 students are now shifting to learning in remote or blended situations.

\section{Acknowledgements}

I want to thank my $\mathrm{PhD}$ committee, Drs. Margaret Early, Steven Talmy and Maureen Kendrick, for their support and thoughtful feedback throughout this research and writing process. I am also thankful to the anonymous reviewers for their helpful feedback. 


\section{References}

Abrams, S.S. (2016). Emotionally crafted experiences: Layering literacies in Minecraft. The Reading Teacher, 70(4), 501-506. http://dx.doi.org/10.1002/trtr.1515

Abrams, S. S., \& Russo, M. P. (2015). Layering literacies and contemporary learning. Journal of Adolescent \& Adult Literacy, 59(2), 131-135.

Black, R. W. (2008). Adolescents and online fan fiction. Peter Lang.

Compton-Lilly, C. (2014). Introduction: Conceptualizing past, present, and future timespaces. In C. Compton-Lilly \& E. Halverson (Eds.), Time and space in literacy research (pp. 1-15). Routledge.

Cope, B., \& Kalantzis, M. (2009). "Multiliteracies": New literacies, new learning. Pedagogies:An International Journal, 4(3), 164-195. http://dx.doi.org/10.1080/15544800903076044

Cope, B., \& Kalantzis, M. (2015). The things you do to know: An introduction to the pedagogy of multiliteracies. In B. Cope \& M. Kalantzis (Eds.), A pedagogy of multiliteracies:Learning by Design (pp.1-36). Palgrave Macmillan.

Cummins, J., \& Early, M. (2011). Introduction. In J. Cummins \& M. Early (Eds.), Identity texts: The collaborative creation of power in multilingual schools (pp. 319). Trentham Books.

Cummins, J., Hu, S., Markus, P., \& Montero, M.K. (2015). Identity texts and academic Achievement: Connecting the dots in multilingual school contexts. TESOL Quarterly,49(3), 555-581. http://dx.doi.org/10.1002/tesq.241

Crystal, D. (2006). Language and internet. Cambridge University Press.

Duff, P. (2008). Case study research in applied linguistics. Lawrence Erlbaum Associates.

Dyson, A.H. (2004). Diversity as a "handful": Toward retheorizing the basis. Research in the Teaching of English, 39 (2), 210-214.

Dyson, A. H. (2013). Rewriting the basics: Literacy learning in children's cultures. Teachers College Press.

Erstad, O., Kumpulainen, K., Mäkitalo, Å., Schorøder, K. C., Pruulmann-Vengerfeldt, P., \& Jóhannsdóttir, T. (2016). Tracing learning experiences within and across contexts. In O. Estrad, K. Kumpulainen, Å. Schorøder, K.C. Schrøder, P. Pruulmann-Vengerfeldt \& T. Jóhannsdóttir (Eds.), Learning across contexts in knowledge society (pp. 1-13). Sense Publishers.

García-Sánchez, I. M., \& Orellana, M. F. (2019). Introduction: Everyday learning: Centering in schools the language and cultural practices of young people from non-dominant groups. In I. M. García-Sánchez \& M. F. Orellana (Eds.), Language and cultural practices in communities and schools: Bridging learning for students from non-dominant groups (pp. 1-23). Routledge.

Gibbons, P. (2015). Scaffolding language, scaffolding learning: Teaching English language learners in the mainstream classroom ( $2^{\text {nd }}$ ed.). Heinemann.

Gee, J. P. (2004). Situated language and learning: A critique of traditional schooling. Routledge.

Heath, S.B., \& Street, B. (2008). On ethnography: Approaches to language and literacy research. Teachers College Press.

Hyvärinen, R., Kangas, M., \& Krokfors, L. (2016). Primary schools crossing boundaries: 
A study on extending learning environments in two Finnish village school contexts. In O. Estrad, K. Kumpulainen, Å. Schorøder, K.C. Schrøder, P. Pruulmann-Vengerfeldt \& T. Jóhannsdóttir (Eds.), Learning across contexts in knowledge society (pp. 131-144). Sense Publishers.

Ito, M., Baumer, S., Bittanti, M., boyd, d., Cody, R., Herr-Stephenson, B., Horst, H.A., Lange, P. G., Mahendran, D., Martínez, K. Z., Pascoe, C. J., Perkel, D., Robinson, L., Sims, C., Tripp, L. (2013). Hanging out, messing around, and geeking out: Kids living and learning with new media. The MIT Press.

Jenkins, H., Ito, M., \& boyd, d. (2016). Participatory culture in a networked era. Polity Press.

Kalantzis, M., \& Cope, B. (2020). The Knowledge Processes. https://newlearningonline.com/learning-by-design/the-knowledge-processes

Kress, G. (2011). What is a mode? In C. Jewitt (Ed.), The Routledge handbook of multimodal analysis (pp. 54-68). Routledge.

Kress, G. R., \& Van Leeuwen, T. (2006). Reading images: The grammar of visual design. Routledge.

Lam, W.S.E. (2000). L2 literacy and the design of self: A case study of a teenager writing on the internet. TESOL Quarterly, 34(3), 457-482. http://dx.doi.org/10.2307/3587739

Lam, W.S.E. (2004). Second language socialization in a bilingual chat room: Global and local considerations. Language Learning \& Technology, 8(3), 44-65.

Lam, W. S. E. (2009). Multiliteracies on instant messaging in negotiating local, translocal, and transnational affiliations: A case of an adolescent immigrant.

Reading Research Quarterly, 44(4), 377-397. http://dx.doi.org/10.1598/RRQ.44.4.5

Lam, W.S.E. \& Warriner, D. (2012). Transnational and literacy: Investigating the mobility of people, languages, texts and practices in contexts of migration. Reading Research Quarterly, 47(2), 191-215

Lange, P. G. (2014). Kids on YouTube: Technical identities and digital literacies. Left Coast Press.

Lemke, J. L. (2004). Learning across multiple places and their chronotopes. Paper presented at American Educational Research Association Annual 2004 Conference, San Diego, CA.

Lotherington, H., \& Paige, C. (2017). Introduction. In H. Lotherington \& C. Paige (Eds.), Teaching young learners in a superdiverse world: Multimodal approaches and perspectives (pp. 1-6). Taylor \& Francis.

Marshall, E., \& Toohey, K. (2010). Representing family: Community funds of knowledge, bilingualism, and multimodality. Harvard Educational Review, 80(2), 221-241.

Nardi, B.A. (2019). My life as a night elf priest: An anthropological account of world of warcraft. The University of Michigan Press.

Petrov, Anton (2014). Using Minecraft in education: A qualitative study on benefits and challenges of game-based education. http://hdl.handle.net/1807/67048

Ribble, M. (2011). Digital citizenship in schools (2 ${ }^{\text {nd }}$ ed.). International Society for technology in Education. 
Rymes, B. (2012). Recontextualizing YouTube: From macro-micro to mass-mediated communication repertoires. Anthropology \& Education Quarterly, 43(2), 214227. http://dx.doi.org/10.1111/j.1548-1492.2012.01170.x

Rose, G. (2016). Visual methodologies: An introduction to researching visual materials ( $4^{\text {th }}$ ed.). Sage.

Rymes, B. (2016). Classroom discourse analysis: A tool for critical reflection (2 $2^{\text {nd }}$ ed.). Routledge.

Saldaña, J. (2016). The coding manual for qualitative researchers $\left(3^{\text {rd }}\right.$ ed.). Sage.

Sheehy, M., \& Leander, K. M. (2004). Introduction. In K. M. Leander \& M. Sheehy (Eds.), Spatializing literacy research and practice (pp. 1-13). Peter Lang Publishing Inc.

The New London Group (1996). A pedagogy of multiliteracies: Designing social futures. Harvard Educational Review, 66, 60-92.

The New London Group (2000). A pedagogy of multiliteracies designing social futures. In B. Cope \& M. Kalantzis (Eds.), Multiliteracies: Literacy learning and the design of social futures (pp. 9-37). Routledge.

Wong, M. M. (2019). "S:ay what you want...:” Rap battles in a technology-enhanced classroom. Canadian Modern Language Review, 72(2), 169-182. https://doi.org/10.3138/cmlr.2018-0155

Wong, M.M.W. (2020). Mobilizing knowledge processes and lifeworld practices across learning spaces: Exploring grade 6 English language learners' inquiry-based learning experiences in a technology-enhanced classroom [Unpublished doctoral dissertation]. University of British Columbia. https://open.library.ubc.ca/cIRcle/collections/ubctheses/24/items/1.0395371

Yadlin-Segal, A., \& Oppenheim, Y. (2020). Whose dystopia is it anyway? Deepfakes and social media regulation. Convergence. https://doi.org/10.1177/1354856520923963

Yi, Y. (2009). Adolescent literacy and identity construction among 1.5 generation students: From a transnational perspective. Journal of Asian Pacific Communication, 19(1), 100-129.

Author Biography

Melanie M. Wong is an Assistant Professor of Teaching at the University of British Columbia. Prior to pursuing her PhD, she was a K-12 educator for over 15 years. She had diverse teaching experiences including as an elementary teacher and various leadership roles. Her research interests include: K-12, ELL, and Technology-Enhanced Classrooms. 